\title{
Расторжение договора найма на сельские работы по законодательству Российской империи
}

\begin{abstract}
Аннотация. Предметом исследования является система юридических норм периода Российской империи о расторжении договора найма на сельские работы. Автором исследуются основания увольнения, закрепленные в «Положении о найме на сельские работы» от 12 июня 1886 г. и практика их реального применения. Проводится сравнительный анализ с правовыми нормами о расторжении договора фабричного найма как основнъмии для рынка наемного труда 1880-1910-х гг. Характеризуются технико-юридические недочеты исследуемых правил, анализируются сочиальный и экономический контекст принятия "Положения о найме на сельские работь»". Методами исследования стали: историко-правовой, формально-юридический, конкретно-исторический, сравнительный, метод анализа, дедукиии, индукиии, диалектический метод. По итогам исследования сделан основной вывод, согласно которому правовая регламентачия расторжения договора найма на сельские работь отвечала мировому и российскому уровню законодательства своего времени. Обшая направленность исследуемьх норм имела консервативно-охранительный характер и отвечала курсу внутренней политики 1880-1890-х г2. В то же время отдельные предписания и подходы были обусловлены обтективными потребностями хозяйства и особенностами труда в аграрной сфере. Более того, некоторые из закреплявиихся правил отличались в сторону смягчения положения рабочего по сравнению с нормами фабрично-заводского права. Имевчиеся технико-юридические недочетъ института увольнения относились в равной мере как к уровню законодательной техники кониа XIX в., так и к суббективному стремлению законодателя сохранить широкий круг полномочий нанимателя.
\end{abstract}

Ключевые слова: фабрично-заводское законодательство, трудовой договор, увольнение работника, история трудового права, система юридических норм, Российская империя, работник, работодатель, применение права, сельскохозяйственное право.

Abstract. The subject of this research is the normative judicial system of the Russian Empire concerning the termination of employment contracts for agricultural works. The author studies the grounds for dismissal prescribed in the "Regulations concerning employment for agricultural works" of the 12 th of June 1886 and the practice of their actual implementation. The article presents a comparative analysis with legislative norms regarding contract termination for factory employment as the main branch of the hired labour market in the 1880-1910s. The author describes the technical and judicial shortcomings of the studied regulations and analyses the social and economic context of adopting the "Regulations concerning employment for agricultural works". The research's methodology is the following: historical-judicial, legalistic, historical, comparative, analysis, deduction, induction, dialectical. On the basis of the research results the author comes to the principal conclusion according to which the legislative regulation of contract termination for agricultural works corresponded to the world's and Russia's levels of legislation of the time. The general direction of the studied norms was of a conservative-protective nature and corresponded to the direction of the internal politics of the 1880-1890s. At the same time certain prescriptions and approaches were caused by both the objective needs of households and the particularities of working in the agricultural sphere. Moreover, some of the established laws differed into the direction of softening the workers' position in comparison to the norms of factory-plant legislation. The existing technical judicial shortcomings regarding the practice of dismissal concerned equally the level of judicial technique of the end of the 19 th century and the law-makers' subjective aims of preserving the employers' wide ranging powers.

Key words: factory-plant legislation, employment contract, employee dismissal, history of labour law, normative judicial system, Russian Empire, employee, employer, law enforcement, agricultural law.

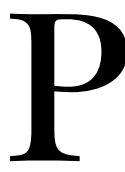

ешение крестьянского вопроса в Российской империи второй половины XIX в. предполагало систему долговременных, не всегда предсказуемых, но необходимых мер. Ликвидация крепостного права в 1861 г. не только стала началом многолетней реформы, но и породила комплекс неизвестных ранее противоречий. Они не были 


\section{История государства и права}

DOI: $10.7256 / 2222-1972.2015 .5 .17297$

преодолены в течение двадцати лет правления Александра II и в том же проблемном состоянии достались Александру III. В эпоху «консервативной реставрации» 1881-1894 гг. крестьянская политика оказалась двойственной. При сохранении свободного состояния крестьянства в деталях конкретных отношений реализовывалась политика усиления роли государства в сельской жизни. При различной оценке обоснованности и успешности проводимых изменений нужно признать, что государство во многом впервые проявило столь последовательное административное внимание к крестьянству. Правительством Александра III подробно регламентировался оборот земли в общине, снижались транспортные тарифы на перевозку аграрной продукции, развивался сельскохозяйственный кредит, оптимизировались выкупные платежи за землю, реформировалось налогообложение, менялась структура сельского самоуправления. С высвобождением масс крестьян качественно новое состояние приобрел рынок наемного труда. С целью его упорядочивания и как ответ на социально-экономические запросы в 1880-е гг. возникает системное законодательство о труде.

В течение всего XIX в. российское фабрично-заводское законодательство постепенно преодолевало инерцию регулирования трудовых отношений в рамках феодальной социальной системы. Именно таковыми являлись характерные черты трудовой сферы вплоть до реформ 1880-х гг. Рабочий, заключая договор трудового найма, поступал в распоряжение нанимателя и подчинялся ему во всем, включая порой даже личную жизнь. Свобода выбора ограничивалась возможностью заключить договор на предлагаемых условиях или не вступать в трудовые правоотношения с нанимателем. Обоснованность такого положения вещей в европейской юридической науке XIX в. доказывалась в теории «свободы договора» [1, 330-332; 2, 181-183; 3, 15]. Права предпринимателя-хозяина в этой системе отношений признавались и гарантировались государством, тогда как соблюдение интересов рабочего зависело от волеизъявления нанимателя. При этом даже после закрепления в 1740 г. [4] и в 1835 г. [5] определенных гарантий для рабочего при увольнении по инициативе нанимателя их реальное исполнение не обеспечивалось должным контролем и санкциями.

Л. С. Таль в работе «Очерки промышленного права» выводил данную систему правоотношений из эволюции средневекового семейного производства: «Промышленное предприятие имеет свои корни в семейном союзе <... Древнейшее предприятие составляло часть или отрасль домашнего хозяйства и всецело подчинялось семейному режиму. Главный контингент работников составляли невольники. На свободных же наемников смотрели как на лиц, добровольно согласившихся на зависимое и приниженное положение. Государство и общество относились совершенно равнодушно к тому, как домовладыка обращался с ними, пока он не нарушал принятых им на себя обязательств или уголовных законов» [6, 3-4]. Приведенная характеристика применима и в оценке института высвобождения работников. Законодательное регулирование данных отношений представлялось государству необходимым лишь в минимальных объемах. В государстве феодального типа, каким являлась Россия до второй половины XIX в., к участию в управлении страной допускались дворянские и высшие торгово-промышленные круги. В результате формирование законодательства о наемном труде приобрело достаточно замедленный характер. Тем не менее к концу XIX в. противостояние различных социальных сил и экономических закономерностей сложилось в пользу развития фабрично-заводского законодательства.

3 июня 1886 г. получили высочайшее утверждение «Правила о надзоре за фабричной промышленностью, о взаимных отношениях фабрикантов и рабочих и об увеличении числа чинов фабричной инспекции» [7]. Правила предварялись «Высочайше утвержденным мнением Государственного совета по проекту Правил о надзоре за фабричной промышленностью». В части увольнения по воле нанимателя закон от 3 июня 1886 г. содержал перечень оснований для такого увольнения. В отличие от неопределенности норм положения 1835 г., были перечислены конкретные обстоятельства, дававшие право нанимателю прекратить трудовое правоотношение. В частности, в соответствии с п. 20 ст. 1 договор найма рабочей силы мог быть расторгнут заведующим фабрикой или заводом по следующим основаниям:

- по усмотрению администрации с предупреждением за две недели;

- вследствие неявки рабочего на работу более трех дней подряд без уважительных причин;

- вследствие привлечения рабочего к следствию и суду по обвинению в преступном 


\section{Исторический журнал: научные исследования № 5 (29) • 2015}

DOI: $10.7256 / 2222-1972.2015 .5 .17297$

действии, влекущем за собой наказание не ниже заключения в тюрьме;

- вследствие дерзости или дурного поведения рабочего, если оно угрожает имущественным интересам фабрики или личной безопасности кого-либо из лиц, принадлежащих к составу фабричного управления;

- вследствие обнаружения у рабочего заразной болезни;

- если сумма денежных взысканий с рабочего превышала треть от причитавшегося ему заработка;

- вследствие приостановки работ на предприятии на продолжительный срок по причине несчастного случая.

Возникновение приведенных норм свидетельствует о достаточно высоком для того времени качестве юридической техники. Примечательно, что российский законодатель первым в мире разделил проступки по степени тяжести и регламентировал расторжение трудового договора неоднократностью совершения трудовых правонарушений. Пункт 18 ст. 1 закона от 3 июня 1886 г. устанавливал обязанность заводоуправления составить правила внутреннего распорядка. К правилам должны были прилагаться табели взысканий со следующим перечнем правонарушений:

- несвоевременная явка на работу или самовольная отлучка с нее;

помещениях установленных правил осторожности в обращении с огнем;

- $\quad$ несоблюдение правил гигиены («чистоты и опрятности»);

- нарушение тишины при работах шумом, криком, бранью, ссорой или дракой;

- непослушание;

- $\quad$ приход на работу в пьяном виде;

- у устройство игр на деньги.

Пункт 30 ст. 1 закона называл также неисправную работу, прогул и нарушение порядка. За все перечисленные проступки администрация уполномочивалась назначать денежные штрафы. Применять штрафы и иные взыскания за другие проступки запрещалось. И только в случае, если штраф превышал треть заработка рабочего, он мог быть уволен. Таким образом, идея градации дисциплинарных проступков и взысканий по степени тяжести получила законодательное оформление. При этом реализовывалась она по принципу, отличному от общепринятого в рассматриваемое время. В поиске наибо- лее эффективных мер обеспечения дисциплины труда законодатель пришел к совмещению дисциплинарной и материальной ответственности. Это в полной мере отвечало мировому уровню развития регулирования трудовых отношений того времени. Однако законодательство оказывало лишь ограниченное влияние на реальную практику трудовых отношений. Низкая эффективность государственного надзора во многом лишала смысла регламентацию оснований и порядка увольнения. В изучаемый период фабричное законодательство Российской империи проходило стадию своего становления и испытывало вполне предсказуемые проблемы. Но важно подчеркнуть, что именно тогда сложилась национальная специфика регулирования увольнения работника.

Одновременно с законом от 3 июня 1886 г. разрабатывалось и было принято «Положение о найме на сельские работы» от 12 июня 1886 г. [8] Статья 58 положения закрепляла общие основания увольнения в области сельскохозяйственного найма:

- леность, нерадение, частые отлучки без позволения нанимателя и неоднократная неисправность рабочего, а также отказ его от исполнения правильных требований нанимателя или лиц, которым вверен надзор за работами и рабочими;

- пьянство, буйство, дерзкие поступки, грубость против нанимателя и членов его семьи, а также открытое неповиновение, оказанное нанимателю или лицам, коим вверен надзор за работами и рабочими;

- похищение имущества, принадлежащего нанимателю, его домашним или лицам посторонним;

- самовольное пользование хозяйским имуществом, умышленное причинение ему вреда и порча хозяйского скота;

- самовольный забор денег или товаров на имя нанимателя и вообще обман его;

- неосторожное обращение рабочего с огнем;

- обнаружение у рабочего заразной болезни;

- неявка или самовольный уход рабочего;

- $\quad$ неоднократное или продолжительное личное задержание рабочего по распоряжению подлежащей власти;

- неспособность рабочего исполнять работу, для которой он нанялся.

Статья 64 «Положения о найме на сельские работы» в своеобразной форме учитывала 


\section{История государства и права}

DOI: 10.7256/2222-1972.2015.5.17297

традицию Юрьева дня, существовавшую в России еще со времен Русской правды. Сторонам договора о найме предоставлялось право расторгнуть соглашение «по истечении первого и каждого следующего года с предварением о том другой стороны не менее как за два месяца до наступления годичного срока найма».

Сравнение норм об увольнении закона от 3 июня 1886 г. («Правил о надзоре за заведениями фабричной промышленности») и «Положения о найме на сельские работы» в отдельных случаях позволяет сделать вывод о более либеральном и диспозитивном характере последнего. Если п. 8 ст. 58 «Положения» за прогул предполагал лишь увольнение рабочего, то примечания к «Правилам о надзоре за заведениями фабричной промышленности» в п. IV устанавливали: «За самовольный отказ от работы до истечения срока найма виновный в том фабричный или заводской рабочий подвергается аресту не свыше одного месяца».

За проступок, аналогичный указанному в п. 4 ст. 58 «Положения о найме на сельские работы», в отношении промышленных рабочих предписывалось: «За умышленное повреждение или истребление находящихся на фабрике или заводе сложных и ценных орудий производства виновный в том рабочий, буде действие его не составляет более тяжкого преступления, подвергается аресту до трех месяцев. Если же последствием такового повреждения или истребления будет остановка работ на фабрике, то виновный подвергается заключению в тюрьме на время от трех месяцев до одного года».

Обращает на себя внимание явно осознанное ужесточение ответственности сельскохозяйственных рабочих за прогул. Если промышленный работник мог быть уволен за отсутствие в течение трех дней подряд, то для наемного крестьянина указание на срок в п. 8 отсутствует. Прогулом для него служит отсутствие в течение любого периода времени.

Специальным основанием для увольнения, неизвестным фабричному праву, являлось право нанимателя освободиться от работника, задержанного волеизъявлением органов власти. Такой подход может показаться достаточно жестким, отвечавшим общей логике ограничения прав рабочего в пользу нанимателя и государства. Однако следует учесть специфику отрасли хозяйства, о которой идет речь. Найм сельскохозяйственных рабочих протекал в условиях короткого периода сбора урожая тех или иных культур. Обстоятельства осложнялись неблагоприятной погодой, изменением финансовой, торговой и транспортной конъюнктуры. Как следствие, потребность в работнике исчислялась днями, а иногда - часами, и наниматель объективно нуждался в оперативных инструментах кадрового управления.

Статья 65 положения, по сути, повторяла пп. «а» п. 20 ст. 1 закона от 3 июня 1886 г. и предоставляла нанимателю возможность расторгнуть договор о найме без специального обоснования, но с предупреждением за две недели. Однако в данном случае допускалась возможность замены предупреждения компенсацией в размере двухнедельного жалованья.

Некоторые формулировки с точки зрения современной юридической техники выглядели расплывчатыми и потенциально благоприятными для злоупотреблений нанимателя. Так, полностью лишенными критериев оценки выступали категории «лености», «нерадения», «буйства», «дерзких проступков», «грубости». Если «неоднократную неисправность рабочего» можно оценить по аналогии с толкованием современного п. 5 ст. 81 Трудового кодекса РФ как повторное (второе) совершение проступка, то понятия «частых отлучек» или «продолжительного личного задержания» полностью лишены способов объективации. Не урегулирована процедура выявления умысла в причинении вреда имуществу нанимателя. Не учитываются возможные уважительные причины задержания работника по распоряжению властей. Впрочем, в последнем случае есть основания полагать, что судом и иными юрисдикционными органами фактор вины и ее формы учитывались даже при отсутствии прямого законодательного предписания. Думается, что причины указанных недочетов относились в равной мере как к объективному уровню юридической техники конца XIX в., так и к субъективному стремлению законодателя сохранить широкий круг полномочий нанимателя.

Нетрудно увидеть в «Положении о найме на сельские работы» большую детализацию оснований увольнения и большую степень свободы нанимателя по сравнению с предписаниями закона от 3 июня 1886 г. Это объясняется несколькими факторами. Регламентация отношений в сельском хозяйстве осуществлялась на достаточно высоком юридическом уровне еще с 1861 г., а установленные тогда нормы поступательно совершенствовались. Сфера действия «Положения о найме на сельские работы» 


\section{Исторический журнал: научные исследования № 5 (29) • 2015}

DOI: $10.7256 / 2222-1972.2015 .5 .17297$

ограничивалась как субъектным составом, так и географически: оно действовало в Виленской, Гродненской, Ковенской, Минской, Могилевской, Смоленской губерниях. Как следствие, принятие данного акта могло восприниматься законодателем как правовой эксперимент, в рамках которого он располагал большей свободой действий, а выбранные решения были потенциально менее опасны. Можно также отметить меньший социальный резонанс по поводу разработки положения, что позволило соответствующим комиссиям реализовать желаемые модели правового регулирования. Так, несмотря на расширение полномочий нанимателя, в положении делалась конструктивная попытка сбалансировать интересы сторон договора о найме. Статья 59 закрепляла: «Если суд не признает правильности увольнения нанимателем рабочего, то, вследствие принесенной последним жалобы, с нанимателя присуждается вознаграждение в размере не свыше трехмесячной наемной платы». С целью гарантирования интересов рабочего закреплялись отдельные элементы процедуры увольнения: «По прекращении договора наниматель обязан возвратить рабочему узаконенный вид» (ст. 66). Особое внимание уделялось обеспечению прав и интересов рабочего: «Наниматель, не исполнивший указанного в предыдущей статье требования, обязан вознаградить рабочего двойною поденною платою по расчету местных в то время цен на его работу за каждый день незаконного удержания узаконенного вида» (ст. 67). «Если при прекращении договора наниматель не удовлетворит рабочих следующею им платою, то последним присуждается сверх причитающегося в их пользу долга особое вознаграждение в размере не свыше двойной суммы сего долга» (ст. 68). Характерно, что в «Правилах о надзоре за заведениями фабричной промышленности» имелась только одна обеспечительная норма, при этом куда более неопределенная по содержанию: «Уволенному на основании сей статьи с фабрики или завода рабочему предоставляется расторжение договора обжаловать суду, который, если признает жалобу основательной, постановляет о вознаграждении рабочего за убытки» (примечание к ст. 20).
На основании сравнения двух источников можно сделать несколько выводов. Юридическая техника российского законодателя конца XIX в. позволяла ему вырабатывать в должной мере сбалансированные трудоправовые институты. Это снимает значительную часть принципиальных замечаний к авторам закона от 12 июня 1886 г. Половинчатость, противоречивость, низкая әффективность данного нормативного правового акта имели во многом осознанный характер и диктовались рабочей политикой государства. Правительство Александра III целенаправленно уходило от компромиссного пути и создавало потенциальный инструмент легитимных репрессий в отношении рабочих. Закономерно, что такой подход вскоре обнаружил свою несостоятельность и создал угрозу для самого государства. Вопреки закономерностям экономического, социального, культурного развития, Россия периода Александра III намеренно консервировалась в состоянии традиционной (аграрной) цивилизации. Ключевым социальным регулятором для таких обществ являются не юридические, а религиозные и этические нормы. В ретроспективе их существование виделось длительным и әффективным, и именно на них пыталась сделать упор власть в эпоху контрреформ 1880-1890-х гг. Однако система отношений с главенством неправовых норм зарождалась еще в догосударственную эпоху, в период позднего палеолита. Одной из ее характеристик была ориентация на небольшие автаркические социумы - племена, союзы племен, протогосударства, ранние государства. Разрастание и усложнение общественных связей приводят к тому, что функциональность нормы определяется ее объективированием, наличием механизмов ее реализации и закреплением правовой санкции. В результате в конце XIX в. Россия представляла собой государство и общество в переходной стадии от феодальной аграрности к индустриализму, когда нравственные императивы уже потеряли прежнюю действенность, но еще не нашли должного юридического замещения. Преодоление этого дуализма было нормальным эволюционным процессом, в ходе которого формировалась отрасль отечественного трудового права.

\section{Библиография:}

1. Таль Л. С. Трудовой договор (цивилистическое исследование). Ярославль: Типография губернского правления, 1918. $422 \mathrm{c}$.

2. Хохлов Е. Б. Очерки истории правового регулирования труда в России. Ч. 1. Правовое регулирование труда в Российской империи. СПб.: Издательский дом Санкт-Петербургского государственного университета, 1999. 196 с. 


\section{История государства и права}

DOI: $10.7256 / 2222-1972.2015 .5 .17297$

3. Лушников А. М. Проблемы общей части российского трудового права: научное наследие, современное состояние и перспективы исследований. Дисс. докт. юр. наук. М.: МГЮА, 2004. 384 с.

4. Регламент и работные регулы на суконные и каразейные фабрики // Полное собрание законов Российской империи. Собрание I. T. XI. СПб.: Типография II Отделения Собственной его императорского величества канцелярии, 1830. № 8440 .

5. Положение об отношениях между хозяевами фабричных заведений и рабочими людьми, поступающими на оные по найму // Полное собрание законов Российской империи. Собрание II. T. Х. СПб.: Типография II Отделения Собственной его императорского величества канцелярии, 1836. № 8157.

6. Таль Л. С. Очерки промышленного рабочего права. М.: Московское научное издательство, 1918. 224 с.

7. Правила о надзоре за фабричной промышленностью, о взаимных отношениях фабрикантов и рабочих и об увеличении числа чинов фабричной инспекции // Полное собрание законов Российской империи. Собрание III. T. VI. CПб.: Государственная типография, 1888. № 3769.

8. Положение о найме на сельские работы // Полное собрание законов Российской империи. Собрание III. T. VI. CПб.: Государственная типография, 1888. № 3803.

\section{References (transliterated):}

1. Tal' L. S. Trudovoi dogovor (tsivilisticheskoe issledovanie). Yaroslavl': Tipografiya gubernskogo pravleniya, 1918. $422 \mathrm{s.}$

2. Khokhlov E. B. Ocherki istorii pravovogo regulirovaniya truda v Rossii. Ch. 1. Pravovoe regulirovanie truda v Rossiiskoi imperii. SPb.: Izdatel'skii dom Sankt-Peterburgskogo gosudarstvennogo universiteta, 1999. $196 \mathrm{s.}$

3. Lushnikov A. M. Problemy obshchei chasti rossiiskogo trudovogo prava: nauchnoe nasledie, sovremennoe sostoyanie i perspektivy issledovanii. Diss. dokt. yur. nauk. M.: MGYuA, 2004. $384 \mathrm{~s}$.

4. Reglament i rabotnye reguly na sukonnye i karazeinye fabriki // Polnoe sobranie zakonov Rossiiskoi imperii. Sobranie I. T. XI. $\mathrm{SPb}$.: Tipografiya II Otdeleniya Sobstvennoi ego imperatorskogo velichestva kantselyarii, 1830. № 8440 .

5. Polozhenie ob otnosheniyakh mezhdu khozyaevami fabrichnykh zavedenii i rabochimi lyud'mi, postupayushchimi na onye po naimu // Polnoe sobranie zakonov Rossiiskoi imperii. Sobranie II. T. X. SPb.: Tipografiya II Otdeleniya Sobstvennoi ego imperatorskogo velichestva kantselyarii, 1836. № 8157.

6. Tal' L. S. Ocherki promyshlennogo rabochego prava. M.: Moskovskoe nauchnoe izdatel'stvo, 1918. $224 \mathrm{~s}$.

7. Pravila o nadzore za fabrichnoi promyshlennost'yu, o vzaimnykh otnosheniyakh fabrikantov i rabochikh i ob uvelichenii chisla chinov fabrichnoi inspektsii // Polnoe sobranie zakonov Rossiiskoi imperii. Sobranie III. T. VI. SPb.: Gosudarstvennaya tipografiya, 1888. № 3769.

8. Polozhenie o naime na sel'skie raboty // Polnoe sobranie zakonov Rossiiskoi imperii. Sobranie III. T. VI. SPb.: Gosudarstvennaya tipografiya, 1888. № 3803 